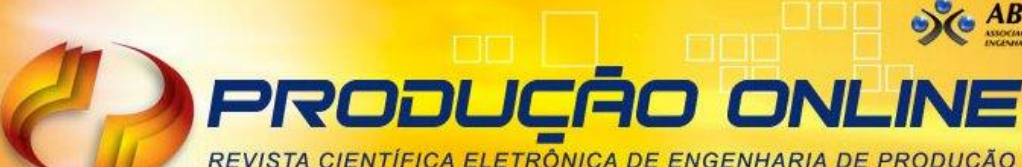 REVISTA CIENTIFICA ELETRÓNICA DE ENGENHARIA DE PRODUÇÃO \\ ISSN 1676-1901
}

\section{UMA ANÁLISE DA GESTÃO OPERACIONAL EM UMA MULTINACIONAL DE ARGAMASSAS INDUSTRIALIZADAS SOB A ÓTICA DOS PRINCÍPIOS LEAN MANUFACTURING}

\section{AN ANALYSIS OF OPERATIONAL MANAGEMENT IN A MULTINATIONAL OF INDUSTRIALIZED MORTARS UNDER THE LEAN MANUFACTURING PRINCIPLES}

\author{
Miriam Ercelita Barbosa* E-mail: miriamercelita@hotmail.com \\ Marcelo Sales Ferreira* E-mail: marcelog@ufrri.br \\ *Universidade Federal Rural do Rio de Janeiro (UFRRJ), Seropédica, SP
}

\begin{abstract}
Resumo : Este trabalho tem como objetivo principal analisar o sistema de gestão de operações de uma empresa de argamassas industrializadas, com múltiplas unidades fabris, sob a ótica da aplicação dos princípios Lean Manufacturing. Pretende-se compreender como esses controles estão implantados e se um diagnóstico baseado na estratégia de gestão é capaz de demonstrar oportunidades de melhoria na gestão de setup de produção; manutenção produtiva total; produção puxada e fluxo continuo; integração da cadeia de suprimentos; gerenciamento visual; controle de qualidade; operações padronizadas; melhoria continua e flexibilização de mão de obra. Assim, para o esse trabalho, a metodologia utilizada foi de caráter descritivo através do estudo de caso, utilizando para coleta e tratamento dos dados questionários aplicados aos gestores das unidades fabris, análise documental, observação participativa da pesquisadora e entrevistas com os gestores regionais. O resultado da pesquisa evidenciou os pontos com oportunidades de melhoria e também unidades fabris com melhores práticas na gestão de operações, que podem ser referências para as demais unidades.
\end{abstract}

Palavras Chaves: Lean Manufacturing. Gestão de Operações. Just in Time. Operações Padronizadas.

Abstract: The main objective of this work is to analyze the operations management system of an industrial mortars company with multiple manufacturing units from the perspective of applying the Lean Manufacturing principles. It is intended to understand how these controls are deployed and show up if diagnosis based on the Lean management strategy is able to demonstrate opportunities for improvement in the management of production setup, total productive maintenance, pull production and continuous flow, supply chain integration, management visual, quality control, standardized operations, continuous improvement and labor flexibility. Thus, for this work, the methodology used was descriptive through the case study, using data collection and treatment applied to managers of the manufacturing units, documentary analysis, participative observation of the researcher and interviews with regional managers. The result of the survey highlighted the points with improvement opportunities.

Keywords: Lean Manufacturing. Operations Management. Just in time. Continuous improvement.

\section{INTRODUÇÃO}

A corrida acelerada pela excelência na produção, ou seja, produzir mais e cada vez melhor, consumindo com eficiência os recursos disponíveis, enseja um estudo de grande interesse para a indústria de modo geral. 
Segundo o relatório preliminar do Sindicato Nacional das Indústrias de Cimento de 2016, as vendas internas de cimento acumularam 57,2 milhões de toneladas, com queda de 11,7\% em relação a 2015. A indústria de argamassas industrializadas é um cliente direto das indústrias cimenteiras, e o comportamento desta indústria reflete também o comportamento econômico das argamassas industrializadas. Dado o contexto recessivo nos dois últimos anos da economia brasileira, faz-se necessária um esforço maior na busca da redução de custo, aumento de produtividade e manutenção da qualidade, sendo factível que as empresas busquem instrumentos de gestão que visem a redução de custos e a estabilidade econômica do negócio. Mediante o exposto, esse estudo é de grande importância para uma empresa como a Argashow, que dada sua capilaridade geográfica necessita uma forte gestão de operações, afim de que atinja a produtividade necessário ao bom andamento do negócio.

O Lean Manufacturing, ou manufatura enxuta, é uma filosofia de gestão oriunda das técnicas desenvolvidas pela Toyota. Tal termo surgiu no final dos anos 80 pelos pesquisadores do IMVP (International Motor Vehicle Program), um programa de pesquisas ligado ao Massachusetts Institute of Technology (MIT), e foi cunhado no livro A máquina que mudou o mundo (Womack, Jones e Roos, 1992). Segundo Sharma e Gary (2007), Ohono demorou vinte anos para implementar completamente o STP, Sistema Toyota de Produção. O primeiro passo do engenheiro foi adaptar as ideias de Henry Ford às suas linhas de montagem, respeitando o mercado japonês. Introduziu o trabalho padronizado, a melhoria continua, a identificação e redução de desperdícios, a manutenção de um ambiente de trabalho limpo e ordeiro.

Tantas vezes uma organização não se considera Lean, por não ter implantando o programa efetivamente, contudo desenvolve práticas e comportamentos que estão alinhados com o Lean Manufacturing (SANTOS et al.,2017). Outras vezes, a companhia tenta implantar as ferramentas, porém encontra resistência em função da enorme mudança de cultura que o programa exige. Diante disso, esse trabalho consiste em analisar as práticas de ferramentas do Lean em uma multinacional de argamassas industrializadas com múltiplas unidades fabris. Pretende-se analisar o sistema de gestão de operações nas unidades fabris da Argashow sob a ótica da aplicação dos princípios Lean Manufacturing, buscando entendimento acerca de como esses controles estão implantados e se um diagnóstico baseado na estratégia de gestão das ferramentas Lean poderiam demonstrar oportunidades de melhoria. 
Este trabalho está dividido em 05 partes: A seção 1 discorre sobre o assunto, sua importância e a contextualização do problema. Na seção 2 apresentam-se alguns conceitos relativos às ferramentas da estratégia e o método de avaliação proposto por Saurin e Ferreira (2008). A seção 3 será a apresentada a metodologia utilizada na pesquisa. A seção 4 os resultados do caso estudado; e finalmente a seção 5 as considerações finais

\section{REFERENCIAL TEORICO}

O Lean é um conjunto de boas práticas que juntamente com um modelo de gestão trazem grandes benefícios às industrias, especialmente sobre a ótica de redução de custos. É encarado como uma filosofia produtiva que organiza a empresa sob o ponto de vista do cliente, reduzindo perdas que não agregam valor ao produto. (TEIXEIRA, 2012).

Conjuntamente, as práticas da produção enxuta constituem-se num sistema de ferramentas, onde os colaboradores são os principais responsáveis por garantir o sucesso desse sistema dentro da organização. Para tanto se faz necessário uma adequação da cultura organizacional aos princípios que norteiam o Lean.

\subsection{Melhoria continua (kaizen)}

Kaizen é uma palavra japonesa para melhoria continua. O kaizen envolve todos os colaboradores da empresa os quais se concentram nas melhorias do processo. $\mathrm{O}$ programa precisa ser patrocinado pela alta direção da organização e disseminado de modo a envolver todos os colaboradores e processo (Liker,2005). O Kaizen estimula o colaborador a observar o processo e redesenhá-lo de uma maneira que agregue algum valor ao produto ou serviço, e traga redução de desperdício seja de tempo ou dinheiro. Pode-se considerar, segundo Siqueira (2005), que o Kaizen é um complemento às práticas de reengenharia. Enquanto a reengenharia promove a melhoria através da inovação, isto é, substituindo os processos utilizados, o Kaizen promove a melhoria através da eliminação de problemas identificados nos processos correntes. 


\subsection{Gerenciamento visual}

Gerenciamento Visual é realizada através de dispositivos instalados ao longo da cadeia produtiva ou administrativa, que permitem a identificação de forma imediata e simples do status do processo e ou de defeitos. Silva (2009), afirmam que a gestão visual de informação pode ser implantada por meio de qualquer dispositivo que comunique rapidamente a existência de alguma anormalidade de desvio no padrão e que indique como o trabalho deve ser padronizado. Os controles visuais são integrados ao processo com agregação de valor. O aspecto visual significa a possibilidade de visualizar um processo, um equipamento, um estoque, uma informação ou mesmo um funcionário desempenhando seu trabalho e imediatamente perceber qual é o padrão aplicado àquela tarefa e se há desvios. (LIKER,2005).

\subsection{JIT Sistema puxado de produção}

Um dos pilares do Lean Manufacturing o JIT - Just in Time ou produção puxada, muitas vezes é confundido com o próprio sistema enxuto de produção. O JIT consiste em um conjunto de técnicas que busca produzir com qualidade no tempo certo e na quantidade necessária. Além da mitigação de desperdícios, a filosofia JIT envolve os colaboradores para produzir com qualidade na quantidade necessária. Para tanto os colaboradores são qualificados e treinados para parar a linha de produção caso percebam qualquer anomalia que irá impedir esse objetivo. (MARTINS e LAUGENI, 2005). O conjunto de implementações sugeridas pelo JIT são amplos do ponto de vista de envolvimento de pessoas. As técnicas por si só não garantem a eficiência do programa, é necessário sedimentar o conhecimento cognitivo da equipe com relação a essa filosofia.

\subsection{Fluxo continuo e takt time}

Para Carvalhosa (2012), o foco global do Lean é o desenvolvimento de fluxo no ambiente produtivo, sendo que esse fluxo deve ser ininterrupto e ao ritmo dos pedidos do cliente, nivelando a carga de trabalho para equipes e equipamentos de modo que não gere ociosidade nem tão pouco acelerações que podem levar a erros e falhas 
na produção. O fluxo contínuo é também utilizado para reduzir as perdas na produção, já que ele busca reduzir o tamanho dos estoques intermediários no processo, minimizando toda e qualquer operação ou movimento que não agregue valor ao produto final. A gestão visual desse fluxo, é feita através do Kanban. (Cirino et al, 2013).

Planejamento - Takt time ou planejamento do ciclo. Takt é uma palavra alemã para ritmo ou compasso, significa a razão da demanda do cliente, a razão na qual o cliente está comprando o produto, (SLAKE, 2005). O Takt time é calculado, dividindo o tempo operacional efetivo (tempo disponível, menos o tempo das paradas planejadas) de um processo pela quantidade de itens que o cliente requer no período. O Takt time deve ser sempre superior ao fluxo continuo, para que não falte produtos para as clientes, contudo não pode ser muito superior para que não gere estoques parados. (CARVALHOSA, 2012).

\subsection{Qualidade}

A qualidade, ao lado do JIT, compõe o segundo pilar do Lean Manufacturing. O sistema desenvolvido pela Toyota privilegia duas características fundamentais para que o sistema seja eficaz: "transfere o máximo de responsabilidade para colaboradores que agregam valor ao produto, e possui um sistema de detecção de defeitos que relaciona cada problema e o trata de forma derradeira" (WOMACK, JONES, ROOS, 1992)

\subsection{Manutenção dos equipamentos}

As quebras nos equipamentos podem provocar inúmeras perdas, tanto de materiais quanto no serviço desenvolvido pelos colaboradores. A busca da qualidade nos serviços e produtos e a alavancagem da produtividade depende do bom funcionamento das maquinas. Autores como Slack, Chambers e Johnston (2002), Martins e Alt (2009), dividem a manutenção em três estágios : a) Manutenção corretiva: no início da era industrial a manutenção era apenas corretiva, a equipe de manutenção era acionada apenas quando acontecia a quebra do equipamento b) A manutenção preventiva é constituída por uma série de ações como limpeza, lubrificação, substituição, calibração e verificação dos equipamentos com o objetivo de reduzir as probabilidades 
das quebras. Essas averiguações são feitas em intervalos predeterminados; c) Manutenção preditiva é aquela realizada antes da quebra do equipamento. Elementos e peças críticas são monitoradas, tendo sua vida útil estimada de acordo com a realidade de cada planta fabril.

\subsection{Cadeia de suprimentos}

O Lean Manufacturing tem como uma de suas premissas, a administração da cadeia de suprimentos com sustentabilidade através dos relacionamentos com os fornecedores. A coordenação colaborativa entre os parceiros da cadeia de suprimentos pode evitar desperdícios tais como: pulmões de estoque devido a ineficiência ou falta de confiabilidade nos parceiros; áreas de estoques desnecessárias; esperas com subutilização de mão de obra, embalagens e insumos obsoletos devido à falta de planejamento na solicitação de compra, retrabalhos (NISHIDA, 2008). As práticas orientadas para produção enxuta devem contar um sistema produtivo integrado, com enfoque no fluxo de produção, produzindo em pequenos lotes, gerando um nível reduzido de estoques, para tanto é necessário que os fornecedores estejam em total sintonia com o sistema JIT, agregando valor através da melhoria continua. (SILVA, 2009)

\subsection{Operações padronizadas}

A definição para trabalho padronizado ou operações padronizadas segundo o Institute Lean Brasil (2017), é o estabelecimento de procedimentos precisos para o trabalho de cada um dos operadores em um processo produtivo baseados no takt time, e na sequência exata que o operador realiza suas tarefas dentro do takt time, considerando também o estoque padrão necessário para cada atividade. No Lean Manufacturing o trabalho padronizado é visto como uma oportunidade de melhoria. Por meio do trabalho padronizado é possível verificar anomalias do processo e corrigilas imediatamente, bem como sugerir uma melhoria nos procedimentos padrões o que origina o Kaizen. (Liker, 2005). Dennis (2008) afirma que o trabalho padronizado é um processo e que não há aprisionamento, sendo que a meta é aperfeiçoar o processo para zerar os desperdícios. 


\subsection{Flexibilização da mão de obra}

A flexibilização da mão de obra consiste em tornar os colaboradores multifuncionais ou polivalentes, sendo assim, um operador pode operar mais de um equipamento ou estar apto a desenvolver mais de uma função na linha de produção. Tendo o colaborador autonomia para resolver problemas, executando o trabalho de forma segura com o conhecimento sistémico das atividades necessárias para a boa execução e conclusão dos trabalhos. (BOGADO, HUG e JUNGLES, 2009)

\subsection{Método de Avaliação Proposto por Saurin e Ferreira (2008)}

A aplicação dos princípios Lean é amplamente adotada pelas empresas na atualidade. Não se restringe somente à indústria, mas expandiu-se também para o comercio e serviços, devido a sua flexibilidade para se adaptar a qualquer seguimento. Contudo a adoção de alguns princípios, não significa exatamente que a empresa pratica a cultura Lean, e, por isso diversos estudos foram desenvolvidos para mensurar o quanto a empresa que adota os princípios está madura em seus projetos. Para Lucato et al. (2006), tão importante quanto transformar as empresas do conceito tradicional para a abordagem enxuta, é avaliar quanto enxutas são essas empresas, para que se possa analisar o progresso dessa transformação. Saurin e Ferreira (2008) desenvolveram um método para avaliar de maneira qualitativa a implantação das práticas de produção enxuta. Segundo os autores Saurin e Ferreira (2008, p.449):

Embora a maturidade de um sistema de produção enxuta esteja associada principalmente à absorção dos princípios enxutos pela cultura organizacional, a avaliação de práticas operacionais associadas a PE, fornece indícios acerca da implantação desse sistema.

Essa declaração dos autores fundamenta que mesmo a empresa não tendo o Lean Manufacturing como um programa oficialmente implantando, ela pode ter características em suas práticas. A princípio, trabalhou-se com a metodologia desses autores em sua íntegra por ser abrangente na abordagem das práticas de chão de fábrica. O instrumento dos autores divide-se em 12 grupos, totalizando 88 perguntas. Para cada pergunta aplica-se um critério de avaliação: Não se aplica (NA), não existe mas 
poderia existir (NE); aplicação muito fraca (MFR); aplicação fraca (MF), aplicação fraca (FR); aplicação forte (FO) e aplicação muito forte (MFO)

\section{METODOLOGIA}

O presente estudo tem uma abordagem descritiva e qualitativa. Quanto ao meio é um estudo de caso, uma vez que tem a pretensão de estudar determinado setor dentro da indústria de argamassas industrializadas com caráter de profundidade e riqueza de detalhes (ROESCH, 2010). Além disso, o questionário foi aplicado a múltiplas unidades fabris, proporcionando a vantagem de comparação de resultados e podendo explicitar unidades benchmarking

A coleta de dados foi realizada utilizando-se o check list proposto por Saurin e Ferreira (2008), onde a cada item da lista foram atribuídas cinco respostas possíveis e para cada resposta um peso, que posteriormente irá compor o resultado quantitativo

\begin{tabular}{ccccccc}
\hline Sigla & NA & NE & MFR & FR & FO & MFO \\
\hline Siganificado & $\begin{array}{c}\text { Não se } \\
\text { aplica }\end{array}$ & $\begin{array}{c}\text { Não } \\
\text { existe,mas } \\
\text { poderia existir }\end{array}$ & $\begin{array}{c}\text { Aplicação } \\
\text { muito } \\
\text { fraca }\end{array}$ & $\begin{array}{c}\text { Aplicação } \\
\text { fraca }\end{array}$ & $\begin{array}{c}\text { Aplicação } \\
\text { forte }\end{array}$ & $\begin{array}{c}\text { Aplicação } \\
\text { muito } \\
\text { forte }\end{array}$ \\
Pontuação & & $\mathbf{2 , 5}$ & $\mathbf{5}$ & $\mathbf{7 , 5}$ & $\mathbf{1 0}$ \\
\hline
\end{tabular}

O resultado se dá por meio da atribuição de pontos para o critério atribuído a cada item:

$$
\text { Nota }=\underline{\text { Nota }=(((B x 2,5)+(C x 5)+(D x 7,5)+(E x 10)) / A}
$$

Onde: (A) é igual ao número de itens aplicáveis; (B) é igual ao número de itens com aplicação muito fraca; (C) é igual ao número de itens com aplicação fraca; (D) é igual ao número de itens com aplicação forte; e $(E)$ é igual ao número de itens com aplicação muito forte.

Vergara (2010) argumenta que a utilização de diferentes fontes de dados promove a triangulação, o que é enriquecedor para o trabalho, por isso, o resultado da aplicação do check list foi apresentado aos gestores da empresa pesquisada, utilizando a entrevista semi-estruturadas como instrumento de coleta de dados.

O check list original de Ferreira e Saurin (2008) foi submetido ao setor de controle de processos e foi designado o gerente da unidade do RJ para fazer as críticas ao questionário, uma vez que o mesmo é especialista em Lean Manufacturing. Após 
a crítica, o questionário foi modificado excluindo o bloco mapeamento do fluxo de valor, por se afirmar que não existia aquela ferramenta na empresa. Cada item foi questionado e avaliado pelo gerente da unidade do Rio de Janeiro, que por sua vez adaptou a linguagem das perguntas para que fossem de fácil compreensão para os respondentes. O resultado do questionário modificado consta do apêndice $A$ desse trabalho e sua versão final teve a redução de 01 bloco e 28 perguntas em relação ao original de Saurin e Ferreira (2008).

\subsection{Descrição resumida da empresa}

A empresa objeto da pesquisa é a Argashow pertencente ao Grupo Samais. $O$ Grupo Samais é uma multinacional fundada em outubro de 1665. Em 351 anos a Samais se expandiu mundialmente projetando, fabricando e distribuindo materiais de construção. Está presente em 66 países, emprega 170 mil colaboradores e mantem 08 centros de pesquisa.

No Brasil a Samais está presente nas cinco regiões brasileiras, com fábricas de tubulações para redes de água e esgoto; fábricas de materiais de construção de diferentes aplicações; fábricas de vidros para construções ou para o mercado automotivo; fábricas de materiais de alta performance para as indústrias de tecnologia; e lojas de distribuição de materiais de construção. Emprega 17 mil funcionários, 56 fábricas, 43 centros de distribuição, 10 mineradores, 41 lojas e 10 escritórios comerciais, e um centro de pesquisa.

A Argashow, por sua vez, iniciou suas atividades na Europa em 1904 e, atualmente, está presente além da Europa, na Ásia e América do Sul. Foi incorporada ao Grupo Samais em julho de 1996, emprega 9.500 pessoas e atua em 46 países.

No Brasil a empresa é líder no seguimento de argamassas industrializadas, detém $30 \%$ de participação do mercado. Sua abrangência é nacional com unidades fabris ou centros de distribuição (CD) em todos os Estados da Federação. A Argashow iniciou em 1998 um ambicioso projeto de expansão: estar presente em todo o território Nacional.

A empresa atende os requisitos da Norma ISO 9000, já qualificada no 2.1.10 desse trabalho, ISO 14000 (normas de gestão ambiental para ambientes de produ- 
ção), OHSAS 18000 (Occupational Health and Safety Assessment Services), cuja tradução é Serviços de Avaliação de Segurança e Saúde Ocupacional. Além disso a Argashow está subordinada a diretrizes e princípios que norteiam o Grupo Samais entre eles um programa de controle interno que é acompanhado por meio de auditorias internacionais do Grupo. A Argashow produz e comercializa argamassas, rejuntes, impermeabilizantes e grautes.

A empresa está organizada da seguinte forma: 17 unidades fabris, 08 Centros de Distribuição e 04 mineradoras. Vide Figura 9.

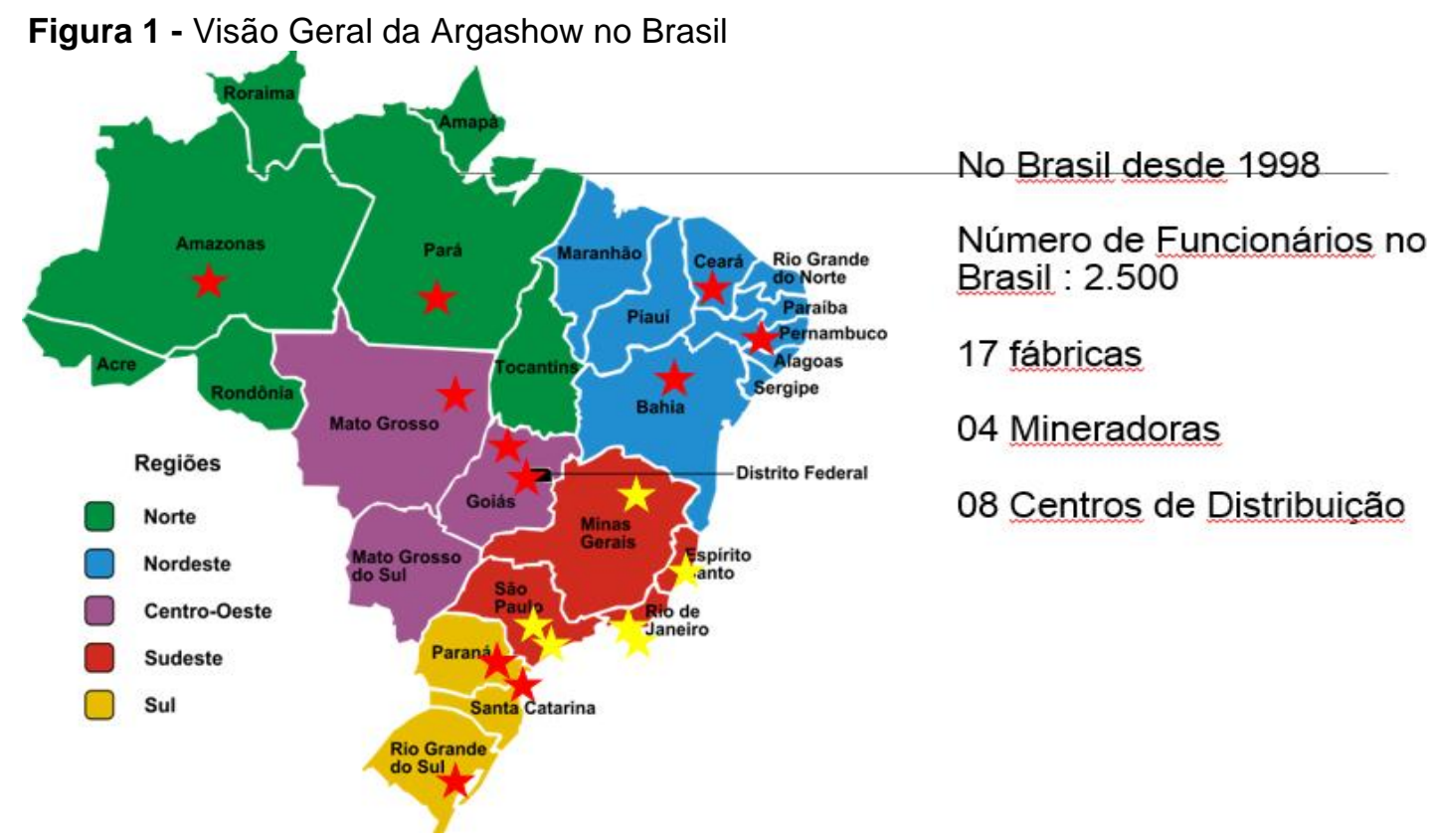

Fonte: dados da pesquisa

\section{RESULTADOS}

O questionário revisado e adaptado à linguagem utilizada na empresa foi submetido à direção da empresa, que aprovou sua aplicação em todas as unidades fabris, excluindo a unidade do Estado de São Paulo, por suas características corporativas não seria uma referência válida. A unidade paulista tem uma estrutura organizacional diferente das demais unidades. Por estar localizada junto ao corporativo, algumas de suas atividades são compartilhadas com a estrutura corporativa, o que dificultaria uma avaliação ponderada.

As fabricas autorizadas foram Anápolis (GO); Aracruz (ES); Benevides (PA); Camaçari (BA); Cuiabá (MT); Itaboraí (RJ); Manaus (AM); Planaltina (GO); Queimados 
(RJ); Santa Luzia (MG); Tubarão (SC); Viamão (RS); Abreu e Lima (PE); Pacatuba (CE) e Ibiporã (PR).

Dentre as 15 fabricas abordadas, doze retornaram com os questionários respondidos, o que resultou em uma amostra $80 \%$ do universo pesquisado. Obteve-se 0 resultado apresentado na Figura 1. As colunas estão agrupadas duas a duas, onde a coluna da esquerda representa o total de pontos alcançados na pesquisa e a coluna da direita representa a pontuação máxima que poderia ser alcançada $A$ linha de comparação representa a relação percentual entre a quantidade de pontos alcançados e o máximo que poderia ser alcançado.

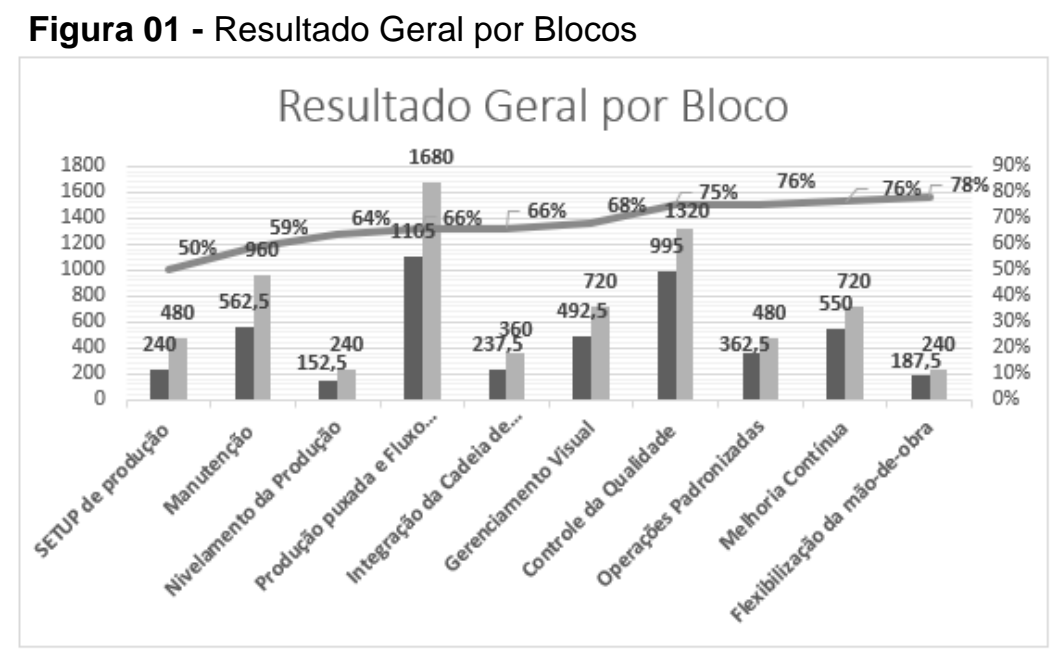

Fonte: Dados da Pesquisa

$\mathrm{Na}$ Figura 02, apresenta-se o resultado por unidade. Cada unidade poderia alcançar a pontuação máxima de 600 pontos. As colunas representam o valor da nota de cada unidade, a linha identifica a relação percentual entre a nota alcançada e a notamáxima:

Figura 02 - Resultado Geral por Unidade

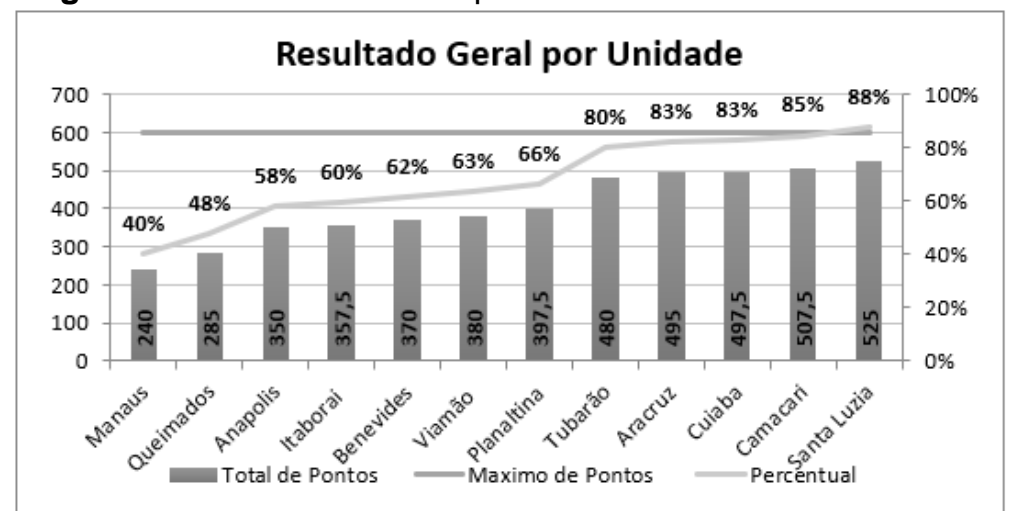

Fonte: Dados da Pesquisa 
Os resultados da pesquisa foram consolidados por região e apesentados aos responsáveis das mesmas para uma análise qualitativa por meio de entrevistas semiestruturadas. As entrevistas obedeceram a um roteiro semiestruturado como recomendado por Roesch (2010), afim de atingir um grau de profundidade a respeito de questões que precisam ser entendidas a partir do conhecimento empírico.

$\mathrm{Na}$ Figura 03 se apresenta a estrutura organizacional da Argashow. Os entrevistados foram os Gerentes Regionais de Operações.

Figura 03 - Estrutura Organizacional Argashow

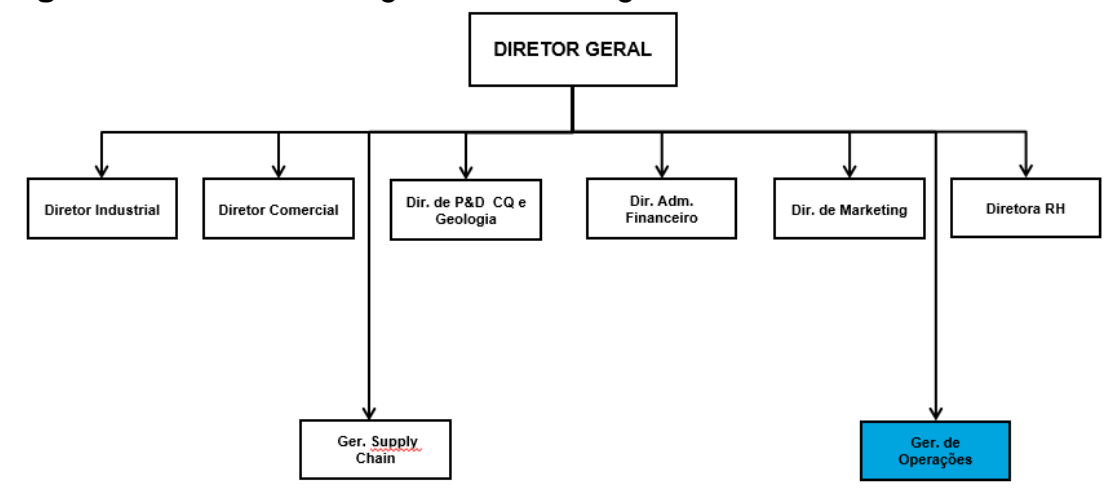

Fonte: dados da pesquisa

Esses profissionais têm como objetivo fazer uma interface entre a diretoria, o comitê diretivo e os gerentes industriais locados nas plantas em todo o território nacional. São duas gerencias regionais de operações: Regional Sul/Sudeste e Regional Norte/Nordeste.

Na regional Sul/Sudeste as unidades respondentes foram: Viamão, Aracruz, Santa Luzia, Cuiabá, Tubarão, Itaboraí e Queimados. Na regional Norte/Nordeste as unidades respondentes foram: Benevides, Manaus, Anápolis, Camaçari e Planaltina.

Os resultados foram apresentados aos gestores regionais de forma individual e os mesmos tiveram contato com os resultados no momento da entrevista, para que as respostas fossem as mais espontâneas possíveis. Foi feito um esclarecimento a respeito dos objetivos acadêmicos do trabalho, bem como foi solicitado uma autorização para que a entrevista fosse gravada.

O gerente regional de operações que analisou os resultados é um profissional que atua no grupo há aproximadamente 30 anos. Durante sua trajetória profissional atuou em várias empresas do grupo e também áreas diversas como desenvolvimento, 
manutenção, área comercial e engenharia. Ao longo desses anos trabalhou em projetos para implantação da filosofia da manufatura enxuta, muito fortemente nos últimos 10 anos.

Inicialmente foi apresentado o gráfico da Figura 04 ao respondente e solicitado sua opinião a respeito dos resultados. O gráfico representa o resultado geral da pesquisa, contemplando todos os blocos da Regional SU/SE. Onde a linha de comparação representa o percentual dos pontos obtidos com relação ao máximo de pontos possíveis. A apresentação está em ordem de melhor resultado considerando o máximo de pontos possíveis por bloco.

Figura 04 - Resultado por Bloco Regional Sul / Sudeste

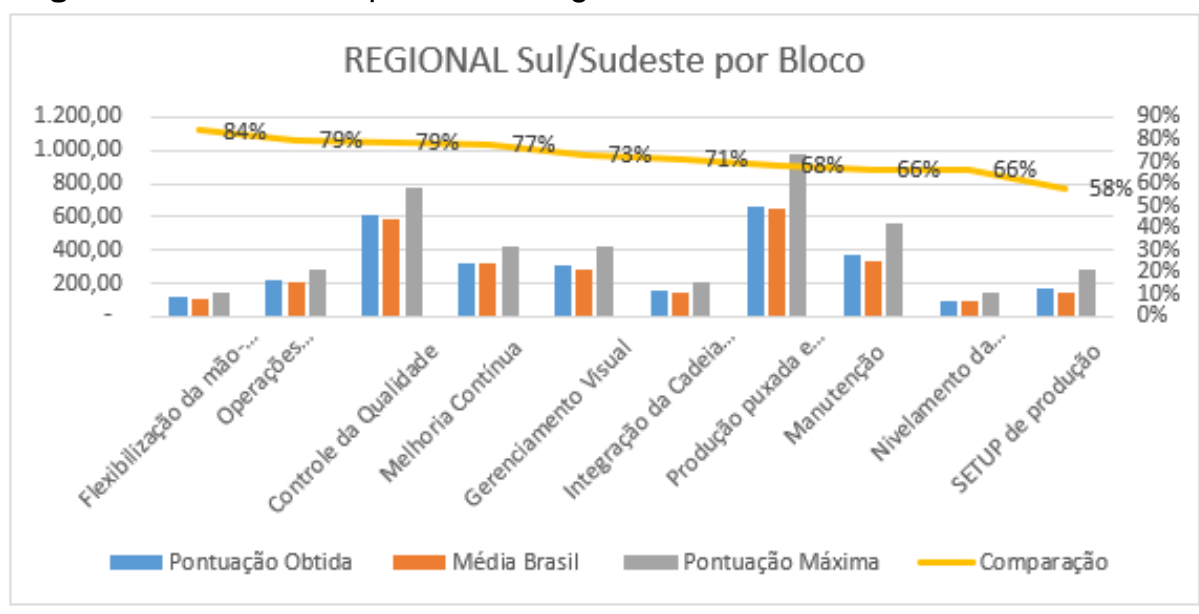

Fonte: Dados da pesquisa

A flexibilização de mão de obra aparece como o bloco de maior identificação de acordo com a percepção dos gerentes que responderam o questionário, o entrevistado achou bastante coerente esse indicativo e explicou que a empresa tem trabaIhado muito fortemente nestes últimos anos para formação de uma equipe polivalente: Corroborou com os resultados dos blocos com menor identificação que foram a manutenção, nivelamento de produção e setup de produção:

"Com relação aos quatros últimos blocos, a manutenção especificamente à parte. Mas a questão do nivelamento da produção, setup de produção, é realmente onde a gente está mais defasado que a gente precisa evoluir junto com a manutenção." (Entrevistado Sul/Sudeste).

Em continuidade com a análise dos dados detalhou a importância do controle de qualidade, e explicou que esse item é de suma importância para a empresa afim 
de que a qualidade dos produtos seja uma percepção de agregação de valor para o cliente, e que esse é um dos objetivos da empresa. Esse é um trabalho continuo junto a gestão industrial e que por isto, esse item aparece como bem pontuado pelos gerentes que responderão ao questionário.

Por outro lado, o entrevistado Sul/Sudeste não se alinhou com o resultado do bloco gestão visual. Em sua visão, esse resultado não reflete a realidade das fábricas, que a empresa ainda tem um bom trabalho a fazer para que se tenha um gerenciamento visual que agregue valor a operação: "acredito que se poderia trabalhar mais fortemente no gerenciamento visual, existe uma defasagem neste item".

Para o entrevistado Sul/Sudeste existem quatro blocos que são fundamentais para o bom andamento da companhia: controle de qualidade, integração da cadeia de fornecedores, manutenção e produção puxada e fluxo continuo. Dentre esses quatro a manutenção e o bloco de produção puxada e fluxo continuo foram mal avaliados de acordo com a percepção dos gerentes operacionais. Ao ser confrontado com essa situação, o entrevistado respondeu de forma direta que a manutenção é o principal ponto de atenção hoje da companhia. Que é um trabalho que está sendo desenvolvido a fim de implantar sistema de gestão de manutenção preventiva e preditiva.

Foi apresentado ao entrevistado Sul/Sudeste o gráfico conforme Figura 05. 0 gráfico representa a regional Sul/SE por unidade, contemplando todos os blocos. Onde a linha de comparação representa o percentual de pontos obtidos com relação ao máximo de pontos possíveis. A apresentação está em ordem de melhor resultado.

Figura 05 - Resultado por Unidades Regional Sul/Sudeste

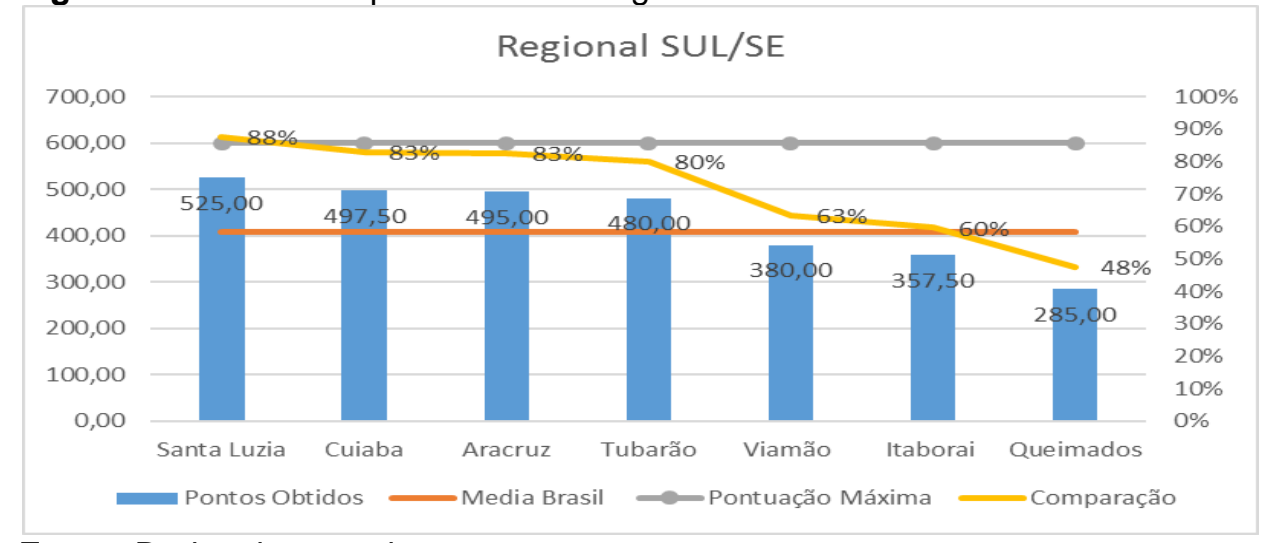

Fonte: Dados da pesquisa 
Ao ser questionado sobre o resultado por unidades, o entrevistado Sul/Sudeste analisou que a unidade de Viamão pontuou abaixo de suas expectativas pois apresenta resultados operacionais muito bons. Afirmou que a unidade de Santa Luzia é realmente benchmarking entre as unidades, inclusive quando verificado seus resultados financeiros. Ao falar das unidades de Queimados e Itaboraí, relacionou o resultado da pesquisa ao nível de conhecimento técnico do gestor respondente com relação a manufatura enxuta, concluindo que os gestores de Viamão, Queimados e Itaboraí são especialistas em Lean Manufacturing e que por isto sua percepção é mais crítica quando comparado com os demais. Afirma que a pesquisa também reflete os resultados de rentabilidade financeira das unidades, que as unidades com as melhores performances financeiras estão em linha com o resultado da pesquisa.

A despeito das estratégias de gestão da companhia serem divulgadas de maneira ampla a todas as unidades, os resultados demonstram que cada unidade recebe e aplica os processos de gestão de maneira diferente. Sobre essa constatação, o entrevistado Sul/Sudeste destacou a maturidade profissional de cada gestor, e também o tempo de operação de cada unidade; quanto maior a idade operacional da unidade, maior é a sua vivencia na aplicação dos procedimentos e assimilação da cultura organizacional. Por isto Santa Luzia, que é a unidade mais antiga do grupo, aparece como uma unidade de referência demonstrando assim a assimilação dos processos através do seu gestor e de sua equipe.

Ao finalizar, o entrevistado constatou que o trabalho é uma fonte de indicadores dos gaps da companhia que precisam ser trabalhados. Que a pesquisa está alinhada inclusive com os resultados financeiros reportados por unidade, com o grau de maturidade profissional dos gestores e com o tempo de operação de cada planta fabril.

$\mathrm{Na}$ regional Norte/Nordeste o profissional que analisou os resultados essa como gerente regional de operações há 05 anos. Trabalha no Grupo há 20 anos. Iniciou sua carreira no grupo como estagiário na divisão vidro, onde permeou os setores de qualidade, comercial e logística. Há 08 anos atua na divisão Argashow, inicialmente como gerente da fábrica de Viamão, e nos últimos 05 anos como gerente regional de operações da regional Norte/Nordeste. O seu conhecimento a respeito do Lean Manufacturing está intrinsicamente relacionado a sua trajetória na companhia, pois, segundo o entrevistado, cada divisão atribui uma roupagem diferente a estratégia da 
manufatura enxuta, porém, os conceitos básicos relacionados a simplificação de processos e a redução de perdas com foco na otimização dos processos, é algo muito antigo dentro do Grupo. Afirmou ainda, que a companhia trabalha exaustivamente na redução de perdas e preservação da qualidade dos produtos.

Foi apresentado ao entrevistado Norte/Nordeste o gráfico da Figura 06 e solicitado sua opinião a respeitos dos resultados

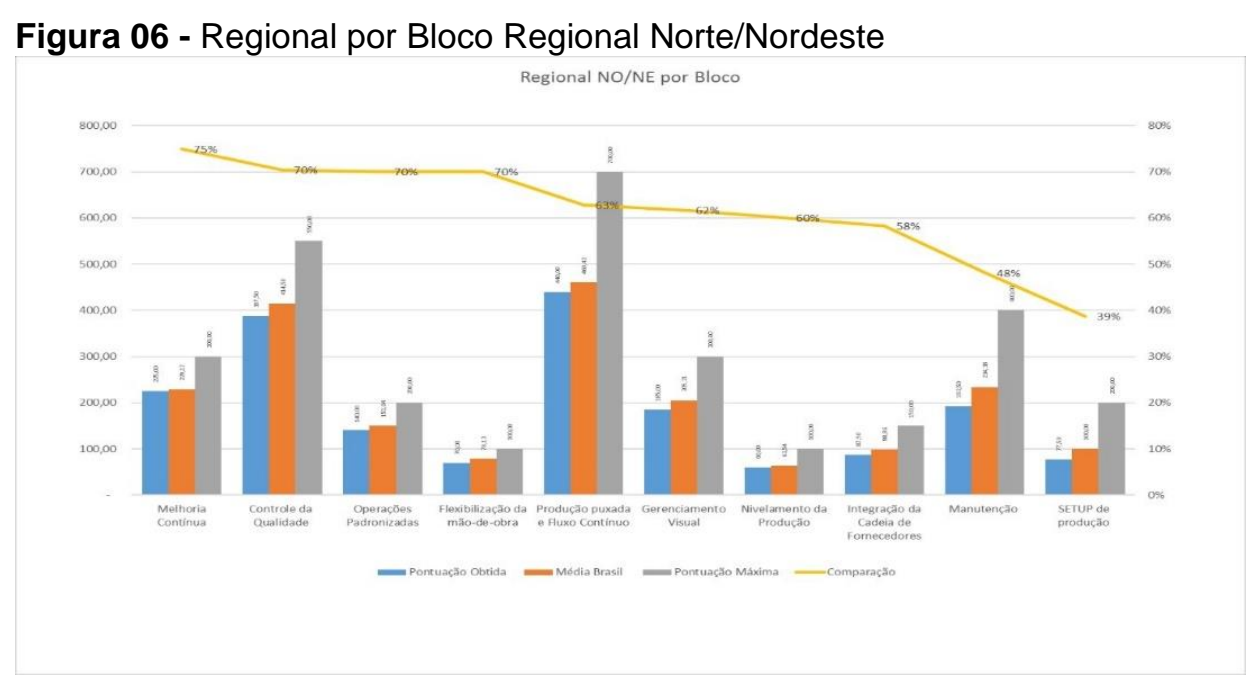

Fonte: dados da pesquisa

$\mathrm{Na}$ regional Norte/Nordeste o bloco que obteve a maior identificação com os respondentes do questionário, foi o bloco de Melhoria Continua, ao ser interpelado sobre esse resultado, o entrevistado achou bastante coerente e ponderou que todos os processos embasados na manufatura enxuta visam o fazer mais empenhando menor recurso. Que para isso é necessário desenvolver um ciclo PDCA, planejando, desenvolvendo, agindo e checando. Para ele, esses check oferecem oportunidade de melhoria ou kaizen. "Nós realmente trabalhamos muito em melhoria continua, não somente na Argashow, mas essa é uma pratica de todo o Grupo, inclusive temos metas corporativas de Kaizens." (Entrevistado Regional Sul/Sudeste)

O entrevistado fez comentários sobre a coerência da sequência dos blocos de operações padronizados e fluxo continuo. Foi possível captar na fala do entrevistado, que a empresa tem uma estrutura de produção planejada de forma inteligente os processos são bem determinados de que forma devem acontecer. A produção é muito similar em todas as unidades o que facilita a disseminação do procedimento. Ainda fez considerações sobre a flexibilização de mão de obra, afirmando que a empresa há 
03 anos trabalha neste projeto, onde o objetivo é dar ao operador a oportunidade de aprendizado do todo. Para o entrevistado, essa é uma questão importante, pois o desenvolvimento de profissionais polivalentes traz amadurecimento e senso crítico para a equipe como um todo. Além de desenvolver as competências pessoais do colaborador gerando oportunidade de desenvolvimento de carreira para o mesmo dentro do grupo. "Passando por vários processos ele desenvolve a análise crítica do processo um pouco mais aguçada, podendo contribuir com sugestões de kaizens".

Para o entrevistado os dois blocos de maior importância para a companhia são a flexibilização de mão de obra e a melhoria contínua. Ele explica que um bloco provoca o desenvolvimento do outro e ambos corroboram em um ciclo virtuoso de aperfeiçoamento dos processos.

O bloco de integração da cadeia de suprimentos surpreendeu ao entrevistado ao pontuar com $58 \%$ de identificação, segundo ele, a cadeia de fornecedores de matérias primas tem um trabalho consolidado e bem integrado aos objetivos da empresa, porém os setores de facilities e MRO ainda demandam trabalho e desenvolvimento. Como também é um ponto de atenção o bloco de manutenção. "A manutenção obteve uma pontuação baixa porque não temos um sistema de manutenção maduro, nossa manutenção é predominantemente corretiva. Ainda estamos longe de um sistema de manutenção planejada." (Entrevistado Norte/Nordeste)

Por esses motivos, o bloco de integração da cadeia de fornecedores e o bloco de manutenção seriam os dois principais pontos de atuação imediata na companhia, na opinião do entrevistado Norte/Nordeste.

Na sequência da análise foi apresentado o gráfico da Figura 07 contendo o resultado por unidade. Foi solicitado ao mesmo emitisse suas considerações a respeito do resultado. 


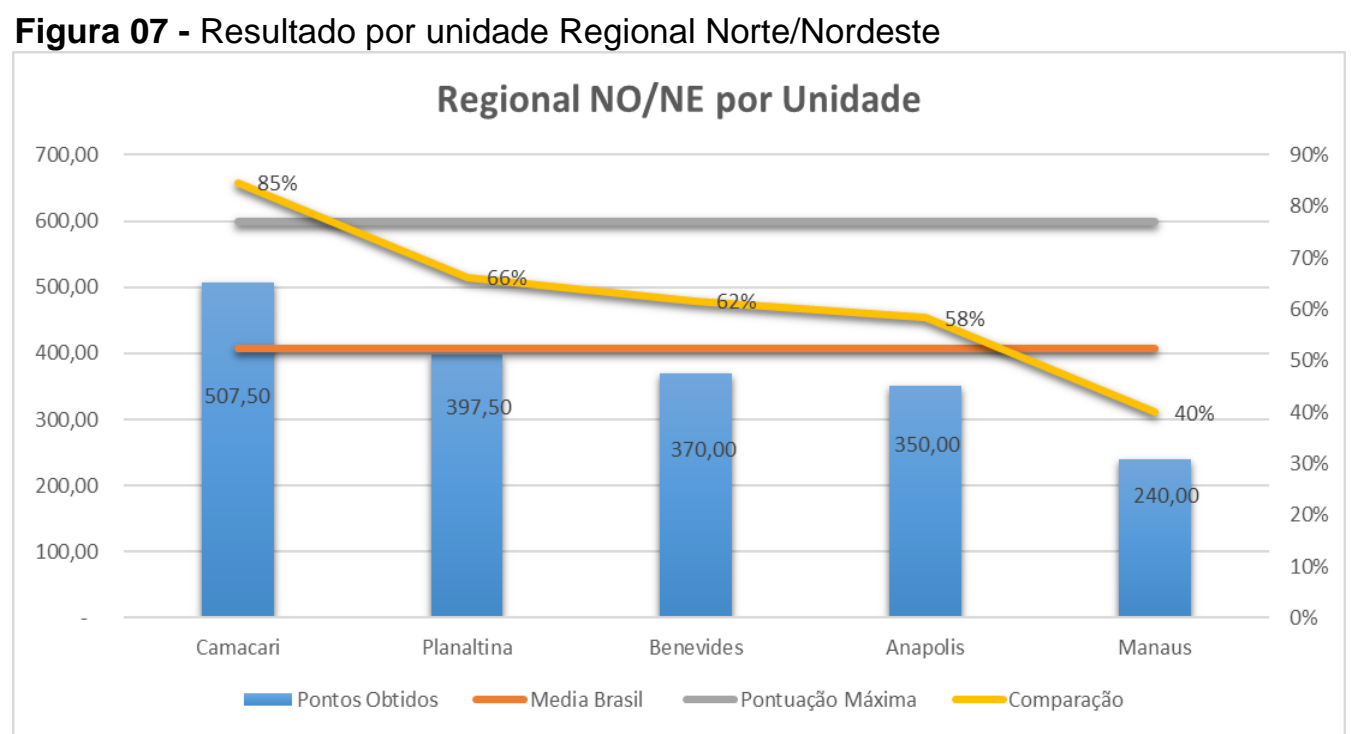

Fonte: Dados da pesquisa

A boa pontuação de Camaçari, segundo o entrevistado, atribui-se a maturidade da equipe que, devido sua experiência, se engaja de modo mais eficiente ao sistema de trabalho. No outro extremo, o entrevistado compara Manaus, que apesar de não ser uma planta nova, mas sofreu um turnover recente em toda a gestão da unidade, bem como de operadores. Mediante problemas de gestão, a filosofia de trabalho ficou comprometida, e por isto esse resultado da fábrica de Manaus está coerente com a realidade, afirmou o entrevistado.

Planaltina, se caracteriza por uma unidade enxuta do ponto de vista de processos e pessoas. "O foco de Planaltina é manter os padrões estabelecidos, sem a incomodação de buscar melhoria continuas”. Já Benevides, é a única planta que ainda não foi automatizada no Brasil, seus processos são manuais, o que de acordo com o entrevistado, prejudica a efetivação de um processo um pouco mais padronizado e desenvolvimento de kaizens.

Anápolis, de acordo o gerente regional de operações, é uma planta muito complexa, onde se tem todas as linhas de produção dos produtos Argashow, inclusive líquidos. Na opinião dele, os processos produtivos de argamassa estão bem consolidados dentro e recebem sugestões de melhorias continuas com muita frequência, mas o processo de fabricação de impermeabilizantes é muito novo na companhia. Por ser uma produção diferente, as aplicações de procedimentos também precisam ser adaptadas. A fábrica de Planaltina, segundo o entrevistado, precisa expandir esse trabalho 
de adequação da linha de impermeabilizante para a filosofia de gestão operacional já existente na empresa.

O entrevistado ratificou que os resultados estão bem condizentes com a realidade das fábricas, voltou a abordar a importância de se trabalhar na cadeia de suprimentos, na manutenção e no setup de produção, que foram os gaps apontados pela pesquisa.

\section{CONSIDERAÇÕES FINAIS}

O questionário foi aplicado em 12 plantas produtivas na Argashow em diferentes estados do Brasil e com níveis de maturidade diversos. As unidades apresentam grandes desafios relacionados a integração dos procedimentos, adaptação das culturas locais, níveis de conhecimento da equipe. Um exemplo disso são os resultados apresentados pelos questionários aplicados nas unidades de Manaus (AM) e Santa Luzia (MG), ambas têm em comum o processo, os objetivos da companhia, uma única gestão corporativa, e apesar de terem o mesmo direcionamento apresentam resultados distintos. Enquanto a unidade mineira é considerada o benchmarking da companhia a unidade de Manaus é repleta de oportunidades de melhoria. Não obstante a média geral da Unidade de Santa Luzia ser superior as demais, observa-se que algumas unidades podem ser referencias em alguns blocos. No Quadro 1, verifica-se as unidades benchmarking:

Quadro 1 - Unidades Benchmarking por bloco.

\begin{tabular}{|l|l|r|r|r|}
\hline \multicolumn{1}{|c|}{ Blocos } & \multicolumn{1}{c|}{ Unidades Benchmarking } & \multicolumn{1}{c|}{$\begin{array}{c}\text { Pontuação } \\
\text { Obtida }\end{array}$} & $\begin{array}{c}\text { Pontuação } \\
\text { Maxima }\end{array}$ & \multicolumn{1}{c|}{$\%$} \\
\hline Flexibilização da mão-de-obra & Aracruz, Cuiaba, Santa Luzia e Tubarão & 20 & 20 & $100 \%$ \\
\hline Gerenciamento Visual & Tubarão & 60 & 60 & $100 \%$ \\
\hline Controle da Qualidade & Cuiaba & 108 & 110 & $98 \%$ \\
\hline Melhoria Contínua & Camaçari e Santa Luzia & 58 & 60 & $96 \%$ \\
\hline Produção puxada e Fluxo Contínuo & Santa Luiza & 133 & 140 & $95 \%$ \\
\hline Operações Padronizadas & Cuiaba & 38 & 40 & $94 \%$ \\
\hline Integração da Cadeia de Fornecedores & Santa Luiza & 28 & 30 & $92 \%$ \\
\hline Manutenção & Tubarão & 70 & 80 & $88 \%$ \\
\hline Nivelamento da Produção & Camaçari e Santa Luzia & 18 & 20 & $88 \%$ \\
\hline SETUP de produção & Cuiabá e Santa Luzia & 28 & 40 & $69 \%$ \\
\hline & & 558 & $\mathbf{6 0 0}$ & $\mathbf{9 3 \%}$ \\
\hline
\end{tabular}

Fonte: Dados da pesquisa

A nota geral da empresa foi de $68 \%$. O Setup da produção foi o bloco com menor identificação entre as unidades. De acordo com a entrevista do Regional 
Norte/Nordeste a unidade de Camaçari oferece um procedimento modelo que tem Ihe garantido um setup eficiente com redução de perdas neste procedimento.

A manutenção foi um bloco que pontuou abaixo da média, e isto se ratificou fortemente nas falas dos entrevistados das Regionais Sul/Sudestes e Norte/Nordeste. Além da não identificação das unidades, os entrevistados afirmaram que a manutenção na companhia acontece majoritariamente de forma corretiva. Essa, sem dúvida, não é uma situação confortável para nenhuma empresa, porque, a manutenção corretiva não planejada eleva os custos em até duas vezes o valor de uma manutenção preventiva, segundo a ABRAMAN (2013), e as perdas de faturamento podem ser imensuráveis.

Outro aspecto a ser ressaltado neste trabalho foi com relação ao alinhamento feito nas entrevistas com os gestores regionais, os quais surpreenderam-se com alguns resultados, como por exemplo a unidade de Viamão, que obteve uma pontuação abaixo do esperado pelo seu gestor regional. O mesmo atribuiu a baixa pontuação ao nível de criticidade do gerente que respondeu a pesquisa. Segundo o gestor regional as devolutivas de Viamão, Queimados e Itaboraí estão alinhadas com o nível de conhecimento dos gestores daquelas unidades, pois os mesmos, por terem uma boa formação no programa Lean, criticaram de maneira mais severa a aplicação das ferramentas. Desse modo se prospectam resultados subjetivos a respeito do nível de conhecimento dos gestores respondentes e também o nível de criticidade com que os mesmos avaliam suas plantas, podendo inferir, que o desempenho operacional obtido para cada unidade está diretamente ligado ao nível de conhecimento dos gestores. Fato este que corrobora a pesquisa de Tortorella et al (2017), onde os autores afirmam em suas conclusões que a melhor orientação de estilo de liderança depende da maturidade da implementação do Lean e do nível do respectivo do líder

Portanto, a análise do sistema de gestão de operações nas unidades fabris da Argashow sob a ótica da aplicação dos princípios Manufacturing, demonstrou que os controles da gestão operacional na empresa estão implantados de maneira parcial e ainda com pouca estabilidade em algumas unidades, sendo que o seu grau de convergência com as ferramentas do Lean apontaram 68\% de identificação com as ferramentas, mas, segundo a opinião dos gestores regionais que revisaram os resultados, é necessário buscar sustentabilidade para esse posicionamento. 
Conclui-se que a aplicação de um questionário para avaliar as práticas do Lean Manufacturing nas empresas pode demonstrar oportunidades de melhoria, ainda que, essa empresa não tenha o Lean como sua estratégia de gestão oficial. É fato relevante que a busca por redução de perdas é um exercício diário das organizações e isto pode ser mapeado através das aplicações Lean. Isto aplica-se sobretudo para organizações industrias com múltiplas instalações produtivas, em que a unidades de melhor desempenho podem constituir-se benchmarkings específicos a serem trabalhados internamente.

\section{REFERÊNCIAS}

BOGADO, J. G.M.; HUG, V.P.; JUNGLES, A. E. (2009). Capacitación en obra para obtener la polivalencia de los operarios y verificación de sus efectos en la construcción civil. Revista Ingeniería de Construcción, v. 24, n. 3, p. 285-309. Disponível em: https://dx.doi.org/10.4067/S0718-50732009000300006. Acesso em: 29 maio 2017.

CARVALHOSA, M.M.F. Proposta de desenvolvimento de um índice em contextos organizados: um estudo de caso. Dissertação (Mestrado) - Programa de Pós-Graduação em Engenharia e Gestão Industrial, Universidade da Beira Interior. Covilhã. Portugal, 2012.

CIRINO, S. R. A. et al. Sistema de Produção Enxuta: analisando as práticas adotadas em uma indústria têxtil paraibana. In: CONGRESSO BRASILEIRO DE MANUTENÇÃO E GESTÃO DE ATIVOS. 28., 2013. Anais... Bauru, Ano 8, no 1, 2013. Disponível em: http://www.abraman.org.br/Arquivos/403/403.pdf. Acesso em: 29 maio 2017.

DENNIS, P. Produção simplificada: um guia para entender o sistema de produção mais poderoso do mundo. 2. ed. Porto Alegre, RS: Bookman, 2008.

LEAN INSTITUTE BRASIL. Institucional. Disponível em: http://www.lean.org.br/o-que-elean.aspx. Recuperado em 29 de maio de 2017

LIKER, J. K. O modelo Toyota: 14 princípios de gestão do maior fabricante do mundo. Lene Belon Ribeiro (trad.) Porto Alegre: Bookman, 2005.

MARTINS, G.; LAUGENI, F. F. Administração de produção. 8. ed. São Paulo: Saraiva, 2005.

MARTINS, P.G.; ALT, P. R. C. Administração de materiais e recursos patrimoniais. São Paulo: Saraiva, 2009.

NISHIDA, L. Logística: conceitos básicos [versão eletrônica]. Lean Institute Brasil. Disponível em: http://www..org.br/artigos/41/logistica--conceitos-basicos.aspx. Acesso em: 05 maio 2016.

ROESCH, S.M. A. Projeto de estagio e pesquisa em administração: guia para estágios, trabalhos de conclusão, dissertações e estudo de casos. Grace Vieira Becker, Maria Ivone de Mello (colaboradoras). ( $3^{a}$ edição). São Paulo. Atlas. 2010 
SANTOS, L. C. et al. Identificação e Avaliação de Práticas de Produção Enxuta em Empresas Calçadistas do Estado da Paraíba. Revista Produção Online, Florianópolis/SC, v. 17, n. 1, p. 176-199, jan./mar. 2017. https://doi.org/10.14488/1676-1901.v17i1.2403

SAURIN, T.A.; FERREIRA, C. F. Avaliação qualitativa da implantação de práticas da produção enxuta: estudo de caso em uma fábrica de máquinas agrícolas. Gestão \&. Produção, São Carlos, v. 15, n. 3, p. 449-462, 2008. https://doi.org/10.1590/S0104$\underline{530 \times 2008000300003}$

SHARMA, A.; GARY, H. O antidoto. 8. ed. São Paulo: Financial Time Prentice Hall. 2007

SILVA, A.M. Avaliação das práticas de Produção Enxuta numa Empresa de Produtos Farmaceuticos. XXIX Encontro Nacional de Engenharia de Produção, Salvador, BA, Brasil, 2009.

Sindicato Nacional das Industrias de Cimento (2017). Resultados Preliminares 2016.Disponível em: http://www.snic.org.br/pdfresultado/Resultados\%20Preliminares\%20Dezembro\%202016\%20v2.pdf. Acesso em; 29 de maio 2017.

SIQUEIRA, J. O sistema de custos como instrumento de apoio ao processo decisório: um estudo multicaso em indústrias do setor metal mecânico da região noroeste do estado do rio grande do sul. Dissertação (Mestrado) - Universidade Regional do Noroeste do Estado do Rio Grande do Sul - UNIJUÍ, ljuí, Brasil, 2005.

SLACK, N.; CHAMBERS, S.; JOHNSTON, R. Administração de produção. São Paulo. Atlas, 2002.

TEIXEIRA, E.S.M. Graus de maturidade da cultura do polo meta mecânico do nordeste de Santa Catarina. Dissertação (Mestrado em Engenharia de Produção) - Programa de Pós-Graduação do Instituto Superior Tupy.Joinville, SC, Brasil. 2012

TORTORELLA, G. L.; FETTERMANN, D.; ANZANELLO; M. Implementação da Manufatura Enxuta e os Comportamentos das Lideranças: Uma Pesquisa Exploratória Lean Manufacturing. Revista Produção Online. Florianópolis/SC, v.17, n. 3, p. 857-882, 2017.

https://doi.org/10.14488/1676-1901.v17i3.2675

VERGARA, S. C. Projetos e relatórios de pesquisa em administração. 14. ed. São Paulo: Atlas, 2013.

WOMACK, J. P.; JONES, D. T.; ROOS, D. A máquina que mudou o mundo. Rio de Janeiro: Campus, 1992.

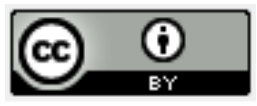

Artigo recebido em: 02/04/2018 e aceito para publicação em: 09/04/2019

DOI: http://dx.doi.org/10.14488/1676-1901.v19i2.3210 